OPEN ACCESS

Approved by: Frontiers Editorial Office, Frontiers Media SA, Switzerland

${ }^{*}$ Correspondence:

Frontiers Production Office production.office@frontiersin.org

Specialty section

This article was submitted to Psychosomatic Medicine, a section of the journal Frontiers in Psychiatry

Received: 22 September 2021 Accepted: 22 September 2021 Published: 18 October 2021

Citation:

Frontiers Production Office (2021) Erratum: Is the Severity of the Clinical

Expression of Anorexia Nervosa Influenced by an Anxiety, Depressive, or Obsessive-Compulsive Comorbidity

Over a Lifetime?

Front. Psychiatry 12:781375

doi: 10.3389/fpsyt.2021.781375

\section{Erratum: Is the Severity of the Clinical Expression of Anorexia Nervosa Influenced by an Anxiety, Depressive, or Obsessive-Compulsive Comorbidity Over a Lifetime?}

\author{
Frontiers Production Office* \\ Frontiers Media SA, Lausanne, Switzerland
}

Keywords: anorexia nervosa, anxiety, depression, nutritional status, body mass index

\section{An Erratum on}

Is the Severity of the Clinical Expression of Anorexia Nervosa Influenced by an Anxiety, Depressive, or Obsessive-Compulsive Comorbidity Over a Lifetime?

by Riquin, E., Raynal, A., Mattar, L., Lalanne, C., Hirot, F., Huas, C., Duclos, J., Berthoz, S., Godart, N., and EVHAN group (2021). Front. Psychiatry 12:658416. doi: 10.3389/fpsyt.2021.658416

Due to a production error, there was an error in the order of the authors. The EVAN group should be listed as the 8th author.

The publisher also wishes to correct the affiliations for Nathalie Godart. The city for affiliation 7 was also corrected to Paris. The corrected author and affiliation lists appear below.

Elise Riquin ${ }^{1,2,3 \dagger}$, Agathe Raynal ${ }^{4 \dagger}$, Lama Mattar ${ }^{5}$, Christophe Lalanne ${ }^{6}$, France $\operatorname{Hirot}^{7,8}$, Caroline Huas $^{7,9}$, Jeanne Duclos ${ }^{10,11}$, EVHAN group, Sylvie Berthoz ${ }^{8,12 \ddagger}$ and Nathalie Godart ${ }^{7,8,9,13 * \text { : }}$

${ }^{1}$ Department of Child and Adolescent Psychiatry, Centre Hospitalier Universitaire d'Angers [Angers University Hospital], Angers, France

2 Laboratory of Psychology, LPPL EA4638, University of Angers, Angers, France

3 Adolescent and Young Adult University Hospital Department of the Health Foundation of Students of France, Centre Pierre Daguet, Sablé-sur-Sarthe, France

${ }^{4}$ Department of Child and Adolescent Psychiatry, $\mathrm{CH}$ du Rouvray-CHU de Rouen, Rouen, France

${ }^{5}$ Nutrition Division, Department of Natural Sciences, School of Arts and Sciences-Lebanese American University, Beirut, Lebanon

${ }^{6}$ Université Paris Diderot [Paris Diderot University], Paris Sorbonne Cité, Paris, France

7 CESP, Univ. Paris-Sud, UVSQ, INSERM U 1178, Université Paris-Saclay [Paris-Saclay University], Paris, France

${ }^{8}$ Department of Psychiatry for Adolescents and Young Adults, Institut Mutualiste Montsouris, Paris, France

9 Adolescent and Young Adult University Hospital Department of the Health Foundation of Students of France, Paris, France

${ }^{10}$ Univ. Lille, CNRS, CHU Lille, UMR 9193-SCALab-Cognitive and Affective Sciences, Lille, France 
11 Hôpital Saint Vincent de Paul, GHICL, Département de Psychiatrie, Paris, France

12 Univ. Bordeaux INCIA CNRS UMR 5287, Bordeaux, France

13 UFR des Sciences de la Santé Simone Veil [Simone Veil Health Science Training and Research Unit], Université de Versailles Saint-Quentin-en-Yvelines [Versailles Saint-Quentin-en-Yvelines University], Versailles, France
The publisher apologizes for this mistake. The original article has been updated.

Copyright (c) 2021 Frontiers Production Office. This is an open-access article distributed under the terms of the Creative Commons Attribution License (CC BY). The use, distribution or reproduction in other forums is permitted, provided the original author(s) and the copyright owner(s) are credited and that the original publication in this journal is cited, in accordance with accepted academic practice. No use, distribution or reproduction is permitted which does not comply with these terms. 